\title{
Mutation analysis in Turkish phenylketonuria patients
}

\author{
M Özgüç, İ Özalp, T Coşkun, E Yılmaz, H Erdem, Ș Ayter
}

\begin{abstract}
Forty-four classical PKU patients have been screened for various mutations. The newly identified IVS 10 splicing mutation was found in $32 \%$ of the mutant alleles and comprises $74.5 \%$ of the mutations that could be typed: $261^{\text {arg-gln }}(6 \cdot 8 \%), 158^{\text {arg- }}$ gly $(2 \cdot 3 \%), 252^{\text {arg-trp }}(1 \cdot 1 \%), 280^{\text {glu-lys }}(-)$, and $272^{\text {gly-stop }}(-)$ were the other mutations that were screened.

( $\mathcal{F}$ Med Genet 1993;30:129-30)
\end{abstract}

Phenylketonuria (PKU), which results from a deficiency of hepatic enzyme phenylalanine hydroxylase (PAH), is a common inborn error of metabolism. The average incidence of PKU is $1 / 10000$ in Caucasians. ${ }^{12}$ The frequency of PKU in Turkey, based on the results of a newborn screening programme in effect since 1983 , is $1 / 4370 .^{3} \mathrm{~A}$ high rate of consanguineous marriages $(21.06 \%)$ in Turkey may be a contributing factor to this high incidence. ${ }^{4}$

Molecular genetic studies of the PAH gene began as a result of the cloning of the cDNA. ${ }^{5}$ The majority of PKU chromosomes are associated with haplotypes $1-4$ as determined by restriction fragment length polymorphisms (RFLPs) created by seven restriction endonucleases. ${ }^{67}$

A previous study of Turkish PKU alleles showed that about $40 \%$ of the mutant alleles are associated with haplotype 6 , a rare haplotype in northern European populations. ${ }^{8}$ Various mutations associated with specific RFLP haplotypes have been determined. ${ }^{9}$

\section{Methods}

We have investigated 44 patients classified as having classical PKU on the basis of initial plasma phenylalanine concentrations and positive urine ferric chloride test for the following mutations: $280^{\text {glu-lys }}, 261^{\text {arg-glu }}, 252^{\text {arg-trp }}, 158^{\text {arg-gln }}$, $272^{\text {gly-stop }}$, and the recently published splicing defect in intron 10 which creates a DdeI restriction enzyme site. ${ }^{10-12}$

PREPARATION OF GENOMIC DNA SAMPLES Peripheral blood was withdrawn in $13 \mathrm{mmol} / 1$ EDTA and leucocytes were separated by centrifugation and lysed in $10 \mathrm{mmol} / 1$ Tris, $10 \mathrm{mmol} / 1 \mathrm{EDTA}, 50 \mathrm{mmol} / 1$ sodium chloride, and $0.2 \%$ sodium dodecyl sulphate in the presence of proteinase $\mathrm{K}(200 \mu \mathrm{g} / \mathrm{ml})$ overnight, followed by repeated phenol-chloroform extractions. DNA was then precipitated by ethanol and resuspended in $0.1 \mathrm{ml}$ TE $(10 \mathrm{mmol} / 1$ Tris-HCl, $0.1 \mathrm{mmol} / 1$ EDTA, pH 7.0). ${ }^{13}$

PREPARATION OF POLYMERASE CHAIN REACTION The oligonucleotide primers $(50 \mathrm{pmol} / 1$ of each) were used with genomic DNA ( 1 to $0.5 \mu \mathrm{g})$ in $1 \times T a q$ DNA polymerase buffer $(25 \mathrm{mmol} / 1 \mathrm{Tris}-\mathrm{HCl}, \mathrm{pH} 9 \cdot 5,50 \mathrm{mmol} / 1 \mathrm{KCl}$, $10 \mathrm{mmol} / 1 \quad \mathrm{MgCl}_{2}, 1 \mathrm{mmol} / 1$ dithiothretiol, $1 \mathrm{mg} / \mathrm{ml}$ bovine serum albumin, $300 \mu \mathrm{g} / \mathrm{ml}$ activated calf thymus DNA), $0.2 \mathrm{mmol} / 1$ each deoxynucleotide (dATP, dGTP, dTTP, dCTP), and $2.5 \mathrm{U}$ Taq DNA Polymerase (Amersham) in a total volume of $0.1 \mathrm{ml}$ reaction mixture (table 1). ${ }^{14}$

\section{Results and discussion}

Table 2 shows the distribution of various mutations in the 88 PKU mutant alleles. Fortytwo percent of the alleles could be identified for a particular mutation and the IVS 10 splicing mutation by itself comprised $75 \cdot 7 \%$ of the mutations identified.

Of 44 patients 11 were homozygous for the IVS 10 splicing mutation, two were homozygous for the codon 261 mutation, and seven

Table 2 Distribution of mutations in the mutant PKU alleles ( $n=88)$. IVS 10 splice mutation comprises $75.5 \%$ of the mutations that could be determined.

\begin{tabular}{lcc}
\hline Mutation & No of alleles & $\%$ of total alleles \\
\hline IVS 10 splice & 28 & 32 \\
261 & 6 & $6 \cdot 8$ \\
158 & 2 & $2 \cdot 3$ \\
252 & 1 & $1 \cdot 1$ \\
280 & 0 & - \\
272 & 0 & $42 \cdot 2$ \\
Total identified & 37 & \\
\hline
\end{tabular}


patients were genetic compounds of whom only one had both alleles identified.

The IVS 10 splicing mutation has been reported to be linked to haplotype 6 in various ethnic groups. ${ }^{15}$ We have also found that 11 of the 12 haplotype 6 alleles are associated with this mutation indicating tight linkage between haplotype 6 and the IVS 10 splicing mutation in our population. Moreover, we found two patients homozygous for the IVS 10 splicing mutation who carried haplotype 16, a rare haplotype (figure).

Interestingly, we have one patient with haplotype $2 / 5$ who is a genetic compound of $261 /$ IVS 10 splicing mutation. We also have one other patient of $2 / 12$ haplotype background who is a genetic compound for $261 /$ - mutations. Both patients' DNA have been checked previously and found not to carry the $408^{\text {arg-trp }}$ mutation which is tightly linked to haplotype 2 in northern European populations. The remaining four alleles bearing the codon 261 mutation are of haplotype 1 background. The codon 280 mutation reported to be found mostly in Mediterranean populations ${ }^{16}$ was not detected in any of the Turkish PKU alleles.

Since the detection of the IVS 10 splicing mutation can be done by a simple non-radioactive test, it is practical to screen our PKU

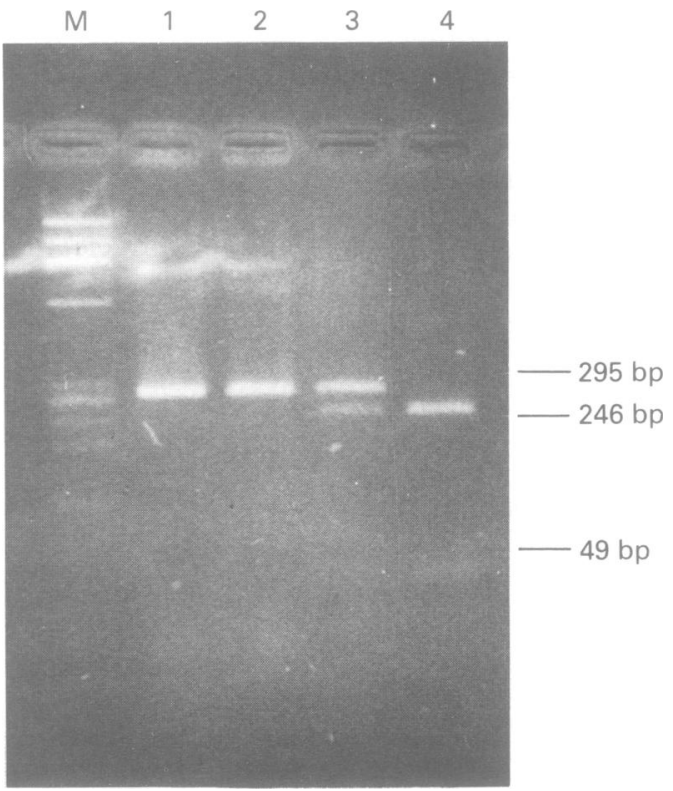

DdeI restriction digest results of amplified DNA from PKU patients. $M=X 174$ HaeIII digest size marker DNA, $1=P C R$ product, $2=$ homozygous normal, $3=$ heterozygote, $4=$ homozygous $P K U$ patient (carries DdeI site on both chromosomes). patients for this mutation. Currently over 600 classical PKU patients are being followed at the Department of Paediatric Metabolism. The low socioeconomic and educational level of the majority of the families, and the prohibitive cost of diet management for our population, are the main causes of demands for prenatal diagnosis. Thus, such direct testing is very valuable.

However, other mutations accounting for the remaining $60 \%$ of the mutant alleles have not been established yet and genotype analysis will still be done by RFLP analysis until more population specific mutations are determined.

This work was supported by grant no TAG 0748 Turkish Scientific Council. We thank Dr Arnold Munnich (INSERM U12, Paris) for the gift of primers.

1 Bickel H, Bachmann C, Bekers R. Neonatal mass screening for metabolic disorders. Eur $\mathcal{F}$ Pediatr 1981;137:133-9.

2 Scriver CR, Kaufman S, Woo SLC. The hyperphenylalaninemias. In: Scriver CR, Beaudet A, Sly W, Valle D, eds. The metabolic basis of inherited disease. 6th ed. New York: McGraw-Hill, 1989:495-546.

3 Özalp I, Coskun T, Tokol S, et al. Inherited metabolic disorder in Turkey. Inher Metab Dis 1990;13:732-8.

4 Ulusoy $M$, Tunçbilek E. Consanguineous marriages in Turkey and its effects on infant mortality. Turk $\mathcal{F}$ Popul Stud 1987;9:7-26.

5 Kwok SCM, Ledley FD, DiLella AG, et al. Nucleotide sequence of a full-length complementary DNA clone and amino acid sequence of human phenylalanine hydroxylase. Biochemistry 1985;24:556-61.

6 Lidsky AS, Ledley FD, DiLella AG, et al. Extensive restriction site polymorphism at the human phenylalanine hydroxylase locus and application in prenatal diagnosis of phenylketonuria. Am f Hum Genet 1985;37:619-34

7 Chakraborty R, Lidsky AS, Daiger SP, et al. Polymorphic DNA haplotypes at the human phenylalanine hydroxylase locus and their relationship with phenylketonuria. Hum Genet 1987;76:40-6.

8 Konecki UL, Schlotter M, Yaylak C, et al. DNA haplotype analysis at the phenylalanine hydroxylase locus in the Turkish population. Hum Genet 1989;81:373-6.

9 Konecki DS, Konecki UL. The phenylketonuria locus: current knowledge about alleles and mutations of the current knowledge about alleles and mutations of the phenylalanine hydroxylase

10 Abadie V, Lyonnet S, Marvin N, et al. CpG dinucleotides are mutation hot spots in phenylketonuria. Genomics 1989;5:936-9.

11 Dworniczak B, Aulehla-Scholz C, Horst J. Phenylketonuria: detection of a frequent haplotype 4 allele mutation. Hum Genet 1989;84:95-7.

12 Dworniczak B, Aulehla-Scholz C, Kalaydjieva L, et al. Aberrant splicing of phenylalanine hydroxylase $\mathrm{mRNA}$ the major cause for phenylketonuria in parts of southern Europe. Genomics 1991;11:242-6.

13 Ostrer H, Fielding HJ. Prenatal diagnosis and carrier detection of genetic diseases by analysis of deoxyribonucleic tion of genetic diseases by analyis

14 Lynch JR, Brown JM. The polymerase chain reaction: current and future clinical applications. $¥$ Med Genet current and

15 Kalaydjieva L, Dworniczak B, Aulehla-Scholz C, et al. Phenylketonuria mutation in southern Europeans. Lance $1991 ; 337: 865-7$.

16 Berthelon M, Caillaud C, Rey F, et al. Spectrum of phenylketonuria mutations in western Europe and north Africa, and their relation to polymorphic DNA haplotypes at the phenylalanine hydroxylase locus. Hum Genet 1991 86:355-8. 